\title{
Prevalence and reasons for use of electronic cigarettes among smokers: Findings from the International Tobacco Control (ITC) Netherlands Survey
}

Citation for published version (APA):

Hummel, K., Hoving, C., Nagelhout, G. E., de Vries, H., van den Putte, B., Candel, M. J. J. M., Borland, R., \& Willemsen, M. C. (2015). Prevalence and reasons for use of electronic cigarettes among smokers: Findings from the International Tobacco Control (ITC) Netherlands Survey. International Journal of Drug Policy, 26(6), 601-608. https://doi.org/10.1016/j.drugpo.2014.12.009

Document status and date:

Published: 01/06/2015

DOI:

10.1016/j.drugpo.2014.12.009

Document Version:

Publisher's PDF, also known as Version of record

\section{Document license:}

Taverne

\section{Please check the document version of this publication:}

- A submitted manuscript is the version of the article upon submission and before peer-review. There can be important differences between the submitted version and the official published version of record. People interested in the research are advised to contact the author for the final version of the publication, or visit the DOI to the publisher's website.

- The final author version and the galley proof are versions of the publication after peer review.

- The final published version features the final layout of the paper including the volume, issue and page numbers.

Link to publication

\footnotetext{
General rights rights.

- You may freely distribute the URL identifying the publication in the public portal. please follow below link for the End User Agreement:

www.umlib.nl/taverne-license

Take down policy

If you believe that this document breaches copyright please contact us at:

repository@maastrichtuniversity.nl

providing details and we will investigate your claim.
}

Copyright and moral rights for the publications made accessible in the public portal are retained by the authors and/or other copyright owners and it is a condition of accessing publications that users recognise and abide by the legal requirements associated with these

- Users may download and print one copy of any publication from the public portal for the purpose of private study or research.

- You may not further distribute the material or use it for any profit-making activity or commercial gain

If the publication is distributed under the terms of Article 25fa of the Dutch Copyright Act, indicated by the "Taverne" license above, 
Research paper

\title{
Prevalence and reasons for use of electronic cigarettes among smokers: Findings from the International Tobacco Control (ITC) Netherlands Survey
}

\author{
Karin Hummel $^{\mathrm{a}, *}$, Ciska Hoving ${ }^{\mathrm{a}}$, Gera E. Nagelhout ${ }^{\mathrm{a}, \mathrm{b}}$, Hein de Vries ${ }^{\mathrm{a}}$, \\ Bas van den Putte ${ }^{\mathrm{c}, \mathrm{d}}$, Math J.J.M. Candel ${ }^{\mathrm{e}}$, Ron Borland ${ }^{\mathrm{f}}$, Marc C. Willemsen ${ }^{\mathrm{a}, \mathrm{b}}$ \\ a Department of Health Promotion, Maastricht University (CAPHRI), P. Debyeplein 1, 6229 HA Maastricht, The Netherlands \\ ${ }^{\mathrm{b}}$ Alliance Smokefree Holland, Eisenhowerlaan 108, 2517 KL The Hague, The Netherlands \\ c Department of Communication, University of Amsterdam (ASCoR), Nieuwe Achtergracht 166, 1018 WV Amsterdam, The Netherlands \\ d Trimbos Institute, Netherlands Institute for Mental Health and Addiction, Da Costakade 45, 3521 VS Utrecht, The Netherlands \\ e Department of Methodology and Statistics, Maastricht University (CAPHRI), P. Debyeplein 1, 6229 HA Maastricht, The Netherlands \\ ${ }^{\mathrm{f}}$ Research Division, The Cancer Council Victoria, 1 Rathdowne St, Carlton, Victoria 3053, Australia
}

\section{A R T I C L E I N F O}

\section{Article history:}

Received 4 August 2014

Received in revised form

28 November 2014

Accepted 9 December 2014

\section{Keywords:}

Smoking

Electronic cigarettes

Addiction

Netherlands

\begin{abstract}
A B S T R A C T
Background: Not much is known about how people in the Netherlands respond to electronic cigarettes (e-cigarettes); how many know about them, which people try them, keep using them and why, and what are changes over time regarding awareness and use?

Methods: We used samples of smokers aged 15 years and older from $2008(n=1820), 2010(n=1702)$, $2013(n=1530)$, and $2014(n=1550)$ as part of the International Tobacco Control (ITC) Netherlands Survey. Reasons for use and characteristics of smokers were examined using the sample from 2014. Logistic regression analyses were conducted to evaluate the associations between smoking-related variables with ever trying e-cigarettes and current e-cigarette use.

Results: In 2014, $91.4 \%$ of Dutch smokers reported being aware of e-cigarettes (97.1\% in $2008,89.2 \%$ in 2010 , and $85.5 \%$ in 2013$), 40.0 \%$ reported having ever tried them $(13.4 \%$ in $2008,14.5 \%$ in 2010 , and $19.6 \%$ in 2013 ), and $15.9 \%$ were currently using them ( $4.0 \%$ in $2008,1 \%$ in 2010 , and $3.9 \%$ in 2013 ). The main reason given for using e-cigarettes was to reduce the number of regular cigarettes smoked per day (79\%). Ever trying e-cigarettes among those aware of e-cigarettes was associated with being young, smoking more regular cigarettes per day, having made a quit attempt in the last year, having used smoking cessation pharmacotherapy in the last year, and reporting high awareness of the price of regular cigarettes. Smokers who kept using e-cigarettes had a higher educational background, had higher harm awareness for the health of others, and were less likely to have a total smoking ban at home.

Conclusion: E-cigarettes are increasingly used by Dutch smokers. Commonly endorsed motivations for current e-cigarette use were to reduce tobacco smoking and because e-cigarettes are considered to be less harmful than tobacco cigarettes.
\end{abstract}

(C) 2014 Elsevier B.V. All rights reserved.

\section{Introduction}

Electronic cigarettes (e-cigarettes) are devices that have been developed to mimic the sensations and pleasure smokers get from regular cigarettes. Some e-cigarettes resemble the appearance of regular cigarettes, while others are designed to look unusual or fashionable. Most e-cigarettes are reusable, and both the prefilled cartridges and the bottles of e-liquid can be bought with or

\footnotetext{
* Corresponding author. Tel.: +31 433882400

E-mail address: Karin.Hummel@maastrichtuniversity.nl (K. Hummel).
}

without nicotine, and with a variety of flavours. They need not have meaningful levels of any toxicant apart from the nicotine if properly manufactured, and as nicotine in the doses they deliver is relatively safe for short term use, their short term safety profile is considered acceptable (Caponnetto et al., 2013; Hajek, Etter, Benowitz, Eissenberg, \& McRobbie, 2014). Long term effects are unknown at this point; therefore, a lot of discussion is still ongoing about their safety and regulation (Borland, 2011; Farsalinos \& Stimson, 2014; Stimson, Thom, \& Costall, 2014; WHO, 2009).

E-cigarettes were introduced to the global market in 2003. In various countries, awareness and use have risen since then (King, Alam, Promoff, Arrazola, \& Dube, 2013; Pepper \& Brewer, 2013; 
Yong et al., 2014). Previous studies were usually limited to studying socio-demographic characteristics of e-cigarette users, while other smoking-related variables to describe e-cigarette users, such as harm awareness of smoking and use of smoking cessation pharmacotherapy, have not been studied yet. Furthermore, little is known about which characteristics distinguish people who try an e-cigarette but stop using it from people who keep using them. The current study examines both socio-demographic characteristics and smoking-related variables of smokers who try e-cigarettes and smokers who keep using them.

To date, few studies about characteristics of users and reasons for using e-cigarettes have been done in Europe. The study of Adkison, O'Connor, Bansal-Travers, et al. (2013) showed marked differences in use across similar countries with different regulatory environments for e-cigarettes. This suggests that the regulatory environment influences awareness, beliefs, and use. Currently, the way e-cigarettes are regulated differs considerably between countries. The Netherlands is an especially interesting case because the legal context for e-cigarettes changed twice within a period of five years. E-cigarettes have been sold in the Netherlands since 2007. They were first classified as consumer products and were commercially promoted and advertised extensively. In 2008, the government claimed that e-cigarettes which contain nicotine should be classified as medicines. This claim was confirmed by a court decision. This decision included an advertisement ban for e-cigarettes, but it was still legal to sell them. At the same time, the government released a public warning about e-cigarettes, saying that not enough information was known about the safety of e-cigarettes. However, in 2012 the classification of e-cigarettes was revised, and they were reclassified as consumer products. This means that advertisements for e-cigarettes were allowed again, and the first mass media advertisements started in 2013. It furthermore means that it is legal to use e-cigarettes in public places like the hospitality industry, while smoking regular cigarettes in the hospitality industry has been prohibited in the Netherlands (with the exception of designated smoking rooms) since 2008 (Nagelhout et al., 2011). Disposable e-cigarettes cost approximately as much as regular cigarettes in the Netherlands, while refillable devices are much cheaper. In our study, we examined awareness and use of e-cigarettes in the Netherlands throughout the changes in the legal context for e-cigarettes between 2008 and 2014.

Previous research reported various reasons for using ecigarettes among smokers and current e-cigarette users: to reduce or quit smoking regular cigarettes, because e-cigarettes are considered to be less harmful than regular cigarettes, to protect the health of the social environment, to avoid smoking bans, because of the lower price of e-cigarettes, because of the better taste and smell of e-cigarettes, out of curiosity, and because of the pleasure of the smoking process which is mimicked by e-cigarettes (Adkison, O'Connor, Bansal-Travers, et al., 2013; Dawkins, Turner, Roberts, \& Soar, 2013; Dockrell, Morison, Bauld, \& McNeill, 2013; Etter \& Bullen, 2011; Etter, 2010; Goniewicz, Lingas, \& Hajek, 2013; Richardson, Pearson, Xiao, Stalgaitis, \& Vallone, 2014; Zhu et al., 2013). The reason that was mentioned most often in most countries was to quit smoking regular cigarettes. Besides quitting, the most often mentioned reasons were to reduce smoking regular cigarettes and because e-cigarettes were considered to be safer/less harmful than regular cigarettes. Next to these main reasons, three more potential reasons were included into the current study, namely whether e-cigarettes were used because of the lower price compared to regular cigarettes, because of the better taste of e-cigarettes, and to avoid smoking bans.

Previous studies focussing on characteristics of e-cigarette users found mixed results. With respect to the association between sociodemographic variables and ever trying e-cigarettes, some studies found that more females had ever tried e-cigarettes (Adkison,
O'Connor, Bansal-Travers, et al., 2013; Regan, Promoff, Dube, \& Arrazola, 2013; Zhu et al., 2013), while other studies found that more males had ever tried them (Choi \& Forster, 2013; Kralikova, Novak, West, Kmetova, \& Hajek, 2013). Furthermore, several studies found that more young people had ever tried e-cigarettes (Choi \& Forster, 2013; Dockrell et al., 2013; Kralikova et al., 2013; Zhu et al., 2013). One study found that a high income was associated with ever trying e-cigarettes (Adkison, O'Connor, Bansal-Travers, et al., 2013) while another one indicated that a low income was related to ever trial (Regan et al., 2013). The same holds true for education: one study found that highly educated people were more likely to ever have used e-cigarettes (Pearson, Richardson, Niaura, Vallone, \& Abrams, 2012), while other studies found that a low education was associated with ever trying them (Regan et al., 2013; Zhu et al., 2013). Regarding current use of e-cigarettes, one study found that a high education was associated with current use (Adkison, O'Connor, Bansal-Travers, et al., 2013), while others reported a relationship with a low educational background (Regan et al., 2013; Zhu et al., 2013), and with being female and young (Zhu et al., 2013). Apparently, no specific user profile can be generated yet.

For the current study, we used a nationally representative sample, while some other studies used only e-cigarette users or smokers with the intention to quit (Etter \& Bullen, 2011; Odum, O'Dell, \& Schepers, 2012). The aim of the current study was to describe the prevalence of e-cigarette awareness and use and to examine characteristics of tobacco smokers who used e-cigarettes in the Netherlands. The following questions were answered: (1) How many smokers were aware of e-cigarettes and used them in 2008, 2010, 2013, and 2014? (2) Why did smokers start to use ecigarettes? (3) What are characteristics of those who ever tried e-cigarette and current e-cigarette users?

\section{Methods}

Sample

Data were derived from the International Tobacco Control (ITC) Netherlands Survey. Dutch tobacco smokers aged 15 years and older were selected from a probability-based web database (Nagelhout et al., 2010). The ITC Survey is a cohort study; respondents are invited to participate and are surveyed each year (Fong et al., 2006). Drop-out is replenished each year by inviting new smokers from the database (Thompson et al., 2006). We used data from the most recent survey wave in which e-cigarette use was assessed: wave 8 , which was conducted in 2014. To investigate the prevalence of awareness and use of e-cigarettes, we additionally used data from wave 1 (2008), wave 4 (2010), and wave 7 (2013). Participants were classified as smokers if they had smoked at least 100 cigarettes in their lifetime and were currently smoking at least monthly (Hyland et al., 2006). A total of 2224 smokers participated in survey wave $1 ; 1702$ smokers were included in survey wave 4 ; 1530 smokers participated in survey wave 7; and 1550 smokers of survey wave 8 were included. Of the smokers who participated in survey wave $1,48 \%$ also participated in survey wave $4,21 \%$ in survey wave 7 , and $16 \%$ in survey wave 8 . We did not include quitters because the sample size of quitters who were currently using e-cigarettes was too small ( $n=0$ in 2008, $n=2$ in 2010, $n=7$ in 2013, and $n=30$ in 2014).

\section{Measurements}

Awareness of, ever trying, and current use of e-cigarettes

Awareness was measured by asking smokers whether they had ever heard of e-cigarettes. If respondents answered 'yes', they were asked whether they had ever used an e-cigarette 
(Adkison, O'Connor, Bansal-Travers, et al., 2013). If these respondents answered 'yes' again, they were considered to have tried e-cigarettes. These smokers were then asked how often they currently used an e-cigarette (daily, at least once a week, at least once a month, less than monthly, or stopped altogether) (Adkison, O'Connor, Bansal-Travers, et al., 2013). Smokers who used an ecigarette at least monthly were considered to be current users. Furthermore, we asked current users whether their e-cigarettes contained nicotine (yes/no/don't know). All e-cigarette users (ever as well as current use) were also tobacco smokers at the time of measurement because we restricted our analyses to current tobacco smokers.

\section{Reasons for use of e-cigarettes}

All current e-cigarette users in the 2014 survey (wave 8) were asked six questions about reasons why they started to use ecigarettes which they could answer with 'yes' or 'no'. The main question was posed as, 'Why did you start using e-cigarettes?', and the six 'yes' or 'no' questions were as follows: (1) 'They may not be as bad for your health', (2) 'They taste better', (3) 'They are cheaper than regular cigarettes', (4) 'So you can smoke in places where smoking regular cigarettes is banned', (5) 'To make it easier to cut down on the number of cigarettes you smoke', (6) 'As a way to help you quit' (Adkison, O'Connor, Bansal-Travers, et al., 2013). Respondents could report more than one reason.

\section{Socio-demographic variables}

Socio-demographic variables were gender, age, income, and education. Age was categorised into the following groups: 15-24 years, 25-39 years, 40-54 years, and 55 years and older. Monthly household income was categorised into three levels: low $(<2000$ euro), moderate (2000-3000 euro), and high ( $>3000$ euro). Respondents who did not answer the income question $(n=334)$ were recorded in a separate category (Hitchman et al., 2012; Nagelhout et al., 2014).

\section{Smoking-related variables}

Smoking-related variables were included in addition to the reasons for using e-cigarettes. To measure harm awareness, respondents were asked how often in the previous month they thought about the harm of their smoking for their own health and the health of others ( $1=$ never, $5=$ very often) (Nagelhout et al., 2012). To assess whether e-cigarettes were used to reduce or quit smoking, we asked how many regular cigarettes respondents smoked per day $(1=<10$ cigarettes, $2=11-15$ cigarettes, $3=16-20$ cigarettes, $4=>20$ cigarettes per day)(Adkison, O'Connor, Borland, et al., 2013), whether they had made a quit attempt in the previous year (yes/no) (Hyland et al., 2006), and whether they had used any smoking cessation pharmacotherapy in the previous year (yes/no) (Kasza et al., 2013). Furthermore, we asked respondents two questions about smoking bans: what the rules about smoking were inside their home ( 1 =smoking is allowed anywhere, 2 =smoking is allowed in some rooms, $3=$ smoking is never allowed inside their home, 4 = smoking is never allowed, except under special circumstances) (Borland et al., 2006) and whether they had smoked tobacco at all during their last visit to a bar or pub (yes/no) (Nagelhout et al., 2011). Finally, respondents were asked how often in the previous month they thought about the money they spent on smoking and how much they enjoyed smoking ( $1=$ never, $5=$ very often $)$ (Siahpush, Borland, \& Yong, 2007).

\section{Analyses}

All analyses were conducted with SPSS version 20.0. Data were weighted by age and gender to be representative for smokers in the Netherlands (Thompson et al., 2006). Assumptions for logistic regression analysis (linearity and multicollinearity) were tested and, in case of non-linearity (education and home smoking ban), this was solved by categorising variables. Completed education was categorised into three groups: low (primary education and lower pre-vocational secondary education), moderate (middle pre-vocational secondary education and secondary vocational education), and high (senior general secondary education, [pre-] university education, and higher professional education). The home smoking ban variable was dichotomised into whether respondents had a total smoking ban at home (yes/no) (Mons et al., 2013).

Descriptive statistics showed the prevalence of awareness of, ever trying, and current use of e-cigarettes in all included waves. Sensitivity analyses with complete cases were performed. These revealed that the pattern of results did not change when only using complete cases.

Logistic regression analyses were used to evaluate the association between socio-demographic and smoking-related variables, with e-cigarette use among smokers in the most recent survey wave (separately for ever trying and current use). We chose to report results of bivariate regression analyses next to multivariate analyses. Besides the multivariate 'forced entry' method, we used the 'backward' method to select predictor variables. By using the 'backward' method, the statistical power was increased as only relevant predictor variables were included in the analysis. Respondents who were aware of e-cigarettes at time of assessment were included in the analyses assessing ever trying them $(n=1550)$. Respondents who had ever used e-cigarettes at time of assessment were included in the analyses for current use $(n=619)$.

Items that were answered with 'refused' or 'don't know' were recoded as missing values and filled using multiple imputations. Pooled estimates were reported where possible; this was not possible for the backward regression analyses because model parameters varied by imputation; therefore, results of the original data were reported for these analyses. Multiple imputations increased the sample size which could be included in the analysis because logistic regression analysis would exclude many cases due to listwise deletion. The only exceptional variable was income; respondents who refused to answer this question were grouped into an extra category because $21.1 \%$ of respondents chose this answering option. The percentage of missing values ('refused' or 'don't know') ranged for all other variables from $0.1 \%$ to $8.4 \%$. The percentage of cases with at least one missing value was 63; therefore the number of imputations was set at 70 (Bodner, 2008). Furthermore, we adjusted for the time a respondent participated in the cohort because previous research has shown that responses can vary as a function of time in sample (Driezen \& Thompson, 2011).

\section{Ethics}

The surveys were cleared for ethics by the Research Ethics Board of the University of Waterloo (ORE \# 18920). Surveys of this kind do not require ethics clearance in the Netherlands.

\section{Results}

\section{Sample description, awareness, and use of e-cigarettes}

Table 1 shows the socio-demographic characteristics of respondents of 2008, 2010, 2013, and 2014. Fig. 1 shows that reported awareness of e-cigarettes decreased between 2008 and 2010 from $97.1 \%$ to $89.2 \%(p<0.001)$ and decreased again to $85.5 \%$ in 2013 $(p<0.01)$, but increased in 2014 to $91.4 \%(p<0.001)$, to around 2010 levels. The percentage of smokers who ever used e-cigarettes increased non-significantly from 2008 (13.4\%) to 2010 (14.5\%) $(p=0.40)$. It increased significantly from 2010 to $2013(19.6 \%)$ 
Table 1

Characteristics of smokers (\%) (weighted data).

\begin{tabular}{|c|c|c|c|c|}
\hline & $\begin{array}{l}\text { Wave } 1 \\
(n=1820)\end{array}$ & $\begin{array}{l}\text { Wave } 4 \\
(n=1702)\end{array}$ & $\begin{array}{l}\text { Wave } 7 \\
(n=1530)\end{array}$ & $\begin{array}{l}\text { Wave } 8 \\
(n=1550)\end{array}$ \\
\hline \multicolumn{5}{|l|}{ Gender } \\
\hline Male & 54.2 & 54.1 & 52.0 & 51.6 \\
\hline \multicolumn{5}{|l|}{ Age group } \\
\hline $15-24$ & 13.8 & 16.5 & 16.8 & 16.8 \\
\hline $25-39$ & 28.5 & 26.8 & 24.6 & 24.1 \\
\hline $40-54$ & 33.9 & 31.9 & 32.1 & 30.9 \\
\hline $55+$ & 23.8 & 24.8 & 26.5 & 28.2 \\
\hline \multicolumn{5}{|l|}{ Income level } \\
\hline Don't want to say/don't know & 22.4 & 28.0 & 30.9 & 29.1 \\
\hline Low & 25.8 & 22.6 & 22.2 & 24.1 \\
\hline Moderate & 24.1 & 20.8 & 19.7 & 19.8 \\
\hline High & 27.8 & 28.7 & 27.1 & 27.0 \\
\hline \multicolumn{5}{|l|}{ Educational level } \\
\hline Low & 38.2 & 36.1 & 28.5 & 25.8 \\
\hline Moderate & 43.0 & 42.4 & 47.2 & 44.2 \\
\hline High & 18.8 & 21.5 & 24.3 & 30.0 \\
\hline \multicolumn{5}{|l|}{ Ever heard of e-cigarettes } \\
\hline Yes & 97.1 & 89.2 & 85.5 & 91.4 \\
\hline \multicolumn{5}{|l|}{ Ever tried e-cigarettes } \\
\hline Yes & 13.4 & 14.5 & 19.6 & 40.0 \\
\hline \multicolumn{5}{|l|}{ Currently using e-cigarettes } \\
\hline Yes & 4.0 & 1.0 & 3.9 & 15.9 \\
\hline \multicolumn{5}{|l|}{ Frequency of current use } \\
\hline Daily & 22.4 & 7.9 & 31.2 & 29.2 \\
\hline At least once a week & 36.7 & 15.6 & 39.4 & 35.7 \\
\hline At least once a month & 18.8 & 2.0 & 9.2 & 13.3 \\
\hline Less than monthly & 22.0 & 74.5 & 20.1 & 21.9 \\
\hline \multicolumn{5}{|c|}{ Current e-cigarette contains nicotine } \\
\hline Yes & Not measured & Not measured & 66.4 & 84.9 \\
\hline No & & & 28.2 & 11.7 \\
\hline Don't know & & & 5.4 & 3.4 \\
\hline
\end{tabular}

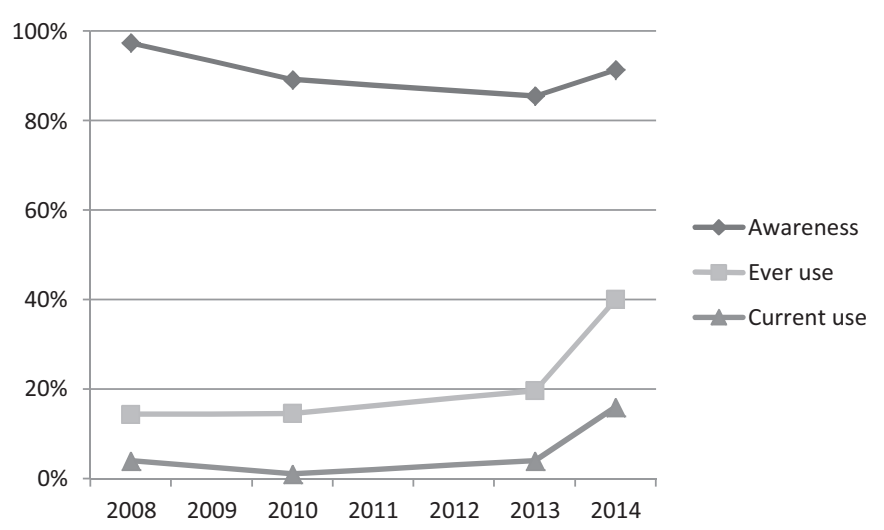

Fig. 1. Trends of awareness, ever use, and current use among smokers.

$(p<0.001)$ and from 2013 to $2014(40.0 \%)(p<0.001)$. The percentage of smokers who were currently using e-cigarettes decreased between $2008(4.0 \%)$ and $2010(1.0 \%)(p<0.001)$. This was followed by an increase between 2010 and $2013(3.9 \%)(p<0.001)$ and a further large increase between 2013 and 2014 (15.9\%) $(p<0.001)$.

Of the current users, most smokers used their e-cigarette at least once a week in 2008 (59.1\%), in 2013 (70.6\%), and in 2014 (64.9\%). In 2010 , far fewer current users used the e-cigarette that often (23.5\%). We asked whether people used e-cigarettes which contained nicotine to respondents in 2013 and 2014. Most people, $66.4 \%$ and $84.9 \%$, respectively, reported that they did.

\section{Reasons for using e-cigarettes}

Respondents who were currently using e-cigarettes in wave 8 (2014) were asked why they started to use e-cigarettes (see Table 2). The reason mentioned most often was that e-cigarettes
Table 2

Reasons for use among smokers and current e-cigarette users $2014(N=246)$ (weighted data).

\begin{tabular}{lc}
\hline & $\%$ \\
\hline $\begin{array}{l}\text { To make it easier to cut down on the number of cigarettes you } \\
\quad \text { smoke }\end{array}$ & 79.0 \\
They may be not as bad for your health & 77.2 \\
Because they are cheaper than regular cigarettes & 61.3 \\
As a way to help you quit & 57.8 \\
So that you can smoke in places where smoking regular cigarettes & 57.4 \\
$\quad$ is banned & \\
As an alternative to quitting & 48.2 \\
Because e-cigarettes taste better than regular cigarettes & 18.1 \\
\hline
\end{tabular}

were used to smoke fewer regular cigarettes (79.0\%), followed by being perceived as less harmful for health than regular cigarettes (77.2\%). Least often mentioned was the better taste of e-cigarettes compared to regular cigarettes (18.1\%).

Characteristics of those ever trying e-cigarettes and current users

Table 3 shows the results of the bivariate and multivariate logistic regression analyses regarding ever trying e-cigarettes among those who reported awareness. Results of the bivariate regression analysis showed that men were more likely to have used e-cigarettes, and respondents of 55 years and older were less likely. Respondents who often thought about the harm of their smoking for their own health were more likely to have used e-cigarettes, as were respondents who smoked more than 20 cigarettes per day, who had made a quit attempt in the previous year, and who used smoking cessation pharmacotherapy in the previous year. Finally, respondents who often thought about the money they spent on smoking had a higher chance of ever having used e-cigarettes.

Results of the multivariate regression analysis with the 'forced entry' method demonstrated that the same variables remained 
Table 3

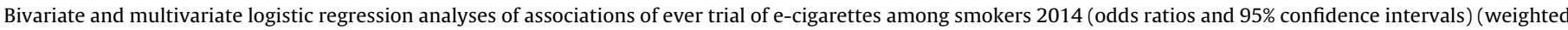
data).

\begin{tabular}{|c|c|c|c|}
\hline & \multicolumn{3}{|c|}{ Ever trial of e-cigarettes } \\
\hline & Bivariate analysis & $\begin{array}{l}\text { Multivariate 'forced } \\
\text { entry' analysis } \\
(n=1270)\end{array}$ & $\begin{array}{l}\text { Multivariate } \\
\text { 'backward' analysis } \\
(n=1118)\end{array}$ \\
\hline \multicolumn{4}{|l|}{ Gender } \\
\hline Female & $0.81(0.66-1.00)^{*}$ & $0.85(0.67-1.09)$ & \\
\hline Male & 1.00 & 1.00 & \\
\hline \multicolumn{4}{|l|}{ Age group } \\
\hline $15-24$ & $1.52(1.09-2.11)^{*}$ & $1.89(1.27-2.82)^{* *}$ & $2.04(1.36-3.06)^{* * *}$ \\
\hline $25-39$ & $2.01(1.50-2.71)^{* * *}$ & $1.99(1.41-2.81)^{* * * *}$ & $2.22(1.57-3.13)^{* * *}$ \\
\hline $40-54$ & $1.71(1.30-2.25)^{* * *}$ & $1.50(1.10-2.05)^{*}$ & $1.62(1.18-2.23)^{* *}$ \\
\hline $55+$ & 1.00 & 1.00 & 1.00 \\
\hline \multicolumn{4}{|l|}{ Income level } \\
\hline Don't want to say & $0.94(0.69-1.27)$ & $0.79(0.56-1.12)$ & \\
\hline Low & $1.15(0.85-1.56)$ & $1.03(0.73-1.46)$ & \\
\hline Moderate & $1.06(0.77-1.45)$ & $0.99(0.70-1.41)$ & \\
\hline High & 1.00 & 1.00 & \\
\hline \multicolumn{4}{|l|}{ Educational level } \\
\hline Low & $0.77(0.58-1.02)$ & $0.84(0.60-1.18)$ & \\
\hline Moderate & $1.05(0.82-1.35)$ & $1.18(0.88-1.57)$ & \\
\hline High & 1.00 & 1.00 & \\
\hline \multicolumn{4}{|l|}{ Harm awareness } \\
\hline Harm awareness self ${ }^{a}$ & $1.20(1.09-1.33)^{* * *}$ & $1.14(0.98-1.32)$ & \\
\hline Harm awareness others ${ }^{\mathrm{a}}$ & $0.97(0.87-1.08)$ & $0.82(0.71-0.96)^{*}$ & \\
\hline \multicolumn{4}{|l|}{ Reduce/quit smoking } \\
\hline \multicolumn{4}{|c|}{ Number of cigarettes per day (only daily smokers) } \\
\hline 10 or less & $0.39(0.28-0.55)^{* * *}$ & $0.40(0.27-0.58)^{* * *}$ & $0.37(0.25-0.54)^{* * *}$ \\
\hline $11-15$ & $0.51(0.36-0.73)^{* * *}$ & $0.51(0.35-0.75)^{* * * *}$ & $0.47(0.32-0.70)^{* * * *}$ \\
\hline $16-20$ & $0.56(0.39-0.82)^{* *}$ & $0.58(0.39-0.85)^{* *}$ & $0.57(0.38-0.84)^{* *}$ \\
\hline More than 20 & 1.00 & 1.00 & 1.00 \\
\hline \multicolumn{4}{|c|}{ Quit attempt made last year } \\
\hline Yes & $2.00(1.59-2.52)^{* * *}$ & $1.51(1.13-2.03)^{* *}$ & $1.52(1.13-2.05)^{* *}$ \\
\hline No & 1.00 & 1.00 & 1.00 \\
\hline \multicolumn{4}{|c|}{ Smoking cessation pharmacotherapy used last year } \\
\hline Yes & $5.52(3.42-8.93)^{* * * *}$ & $3.74(2.18-6.41)^{* * *}$ & $3.59(2.07-6.22)^{* * *}$ \\
\hline No & 1.00 & 1.00 & 1.00 \\
\hline \multicolumn{4}{|c|}{ Avoid smoking bans } \\
\hline \multicolumn{4}{|c|}{ Having a total smoking ban at home } \\
\hline Yes & $0.86(0.68-1.08)$ & $0.88(0.66-1.16)$ & \\
\hline No & 1.00 & 1.00 & \\
\hline \multicolumn{4}{|c|}{ Smoking in bar/pub last visit } \\
\hline Yes & $1.07(0.87-1.33)$ & $0.79(0.61-1.02)$ & $0.79(0.61-1.02)$ \\
\hline No & 1.00 & 1.00 & 1.00 \\
\hline Price awareness ${ }^{\mathrm{a}}$ & $1.29(1.17-1.42)^{* * * *}$ & $1.15(1.01-1.30)^{*}$ & $1.16(1.04-1.31)^{*}$ \\
\hline Enjoy smoking ${ }^{\mathrm{a}}$ & $1.09(0.98-1.22)$ & $1.07(0.94-1.22)$ & \\
\hline \multicolumn{4}{|l|}{ 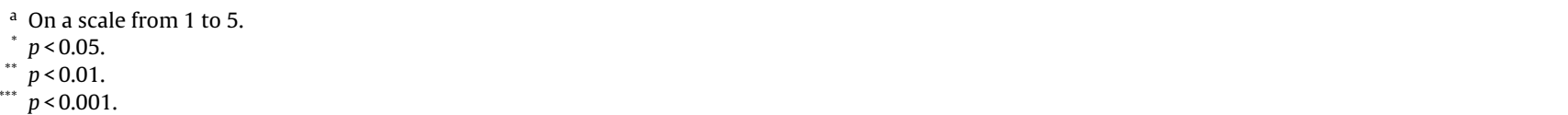 } \\
\hline
\end{tabular}

significantly associated with ever having used e-cigarettes, except for gender and harm awareness for own health. Instead, often thinking about the harm of smoking for the health of other people was associated with a lower chance of ever having used an ecigarette. When conducting a multivariate logistic regression with the 'backward' method, the association with harm awareness for the health of other people disappeared again while the association with the other variables as in the analysis with the 'forced entry' method remained significant.

Table 4 shows the results of the bivariate and multivariate logistic regression analyses which investigate associations between socio-demographic and smoking-related factors on the one hand and current e-cigarette use on the other hand among those ever trying e-cigarettes. Results of the bivariate regression analysis revealed that respondents of the lowest age groups (15-24 years and 25-39 years) were less likely to currently use e-cigarettes than smokers of 55 years and older. Furthermore, respondents with a moderate educational background were less likely to currently use e-cigarettes than highly educated smokers. Moreover, respondents who often thought about the harm of their smoking for the health of other people were more likely to keep using e-cigarettes. Smokers who had a total smoking ban at home and who had smoked during their last visit to a bar or pub were less likely to be current e-cigarette users.

In a multivariate logistic regression with the 'forced entry' method, the association of education, harm awareness for the health of other people, and having a smoking ban at home remained significant in the model. Furthermore, smokers who often thought about the harm of smoking for their own health were less likely to currently use e-cigarettes. Respondents who smoked 11-15 cigarettes per day were more likely to be current users than respondents smoking more than 20 cigarettes per day. In a multivariate logistic regression with the 'backward' method, the same variables remained significantly associated with current use as in the analysis with the 'forced entry' method.

\section{Discussion}

The aim of the current study was to gain insight into the prevalence, motives, and characteristics of smokers who are using 
Table 4

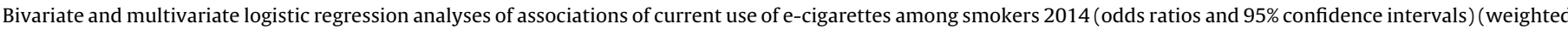
data).

\begin{tabular}{|c|c|c|c|}
\hline & \multicolumn{3}{|c|}{ Current use of e-cigarettes } \\
\hline & Bivariate analysis & $\begin{array}{l}\text { Multivariate 'forced } \\
\text { entry' analysis } \\
(n=598)\end{array}$ & $\begin{array}{l}\text { Multivariate } \\
\text { 'backward' analysis } \\
(\mathrm{n}=523)\end{array}$ \\
\hline \multicolumn{4}{|l|}{ Gender } \\
\hline Female & $1.16(0.84-1.62)$ & $1.25(0.85-1.83)$ & \\
\hline Male & 1.00 & 1.00 & \\
\hline \multicolumn{4}{|l|}{ Age group } \\
\hline $15-24$ & $0.48(0.28-0.85)^{*}$ & $0.52(0.26-1.03)$ & $0.54(0.28-1.06)$ \\
\hline $25-39$ & $0.61(0.37-0.98)^{*}$ & $0.78(0.44-1.37)$ & $0.70(0.41-1.20)$ \\
\hline $40-54$ & $1.33(0.85-2.08)$ & $1.58(0.95-2.63)$ & $1.64(0.99-2.73)$ \\
\hline $55+$ & 1.00 & 1.00 & 1.00 \\
\hline \multicolumn{4}{|l|}{ Income level } \\
\hline Don't want to say & $0.92(0.56-1.52)$ & $0.96(0.54-1.71)$ & \\
\hline Low & $0.80(0.51-1.26)$ & $0.63(0.36-1.08)$ & \\
\hline Moderate & $0.82(0.51-1.33)$ & $0.94(0.54-1.62)$ & \\
\hline High & 1.00 & 1.00 & \\
\hline \multicolumn{4}{|l|}{ Educational level } \\
\hline Low & $0.98(0.63-1.54)$ & $0.89(0.53-1.49)$ & $0.82(0.49-1.40)$ \\
\hline Moderate & $0.54(0.37-0.79)^{* * *}$ & $0.52(0.33-0.81)^{* * *}$ & $0.56(0.36-0.87)^{*}$ \\
\hline High & 1.00 & 1.00 & 1.00 \\
\hline \multicolumn{4}{|l|}{ Harm awareness } \\
\hline Harm awareness self ${ }^{\mathrm{a}}$ & $0.93(0.79-1.10)$ & $0.68(0.53-0.87)^{* *}$ & $0.73(0.58-0.92)^{* *}$ \\
\hline Harm awareness others ${ }^{\mathrm{a}}$ & $1.20(1.01-1.42)^{*}$ & $1.32(1.03-1.70)^{*}$ & $1.31(1.04-1.64)^{*}$ \\
\hline \multicolumn{4}{|c|}{ Reduce/quit smoking } \\
\hline \multicolumn{4}{|c|}{ Number of cigarettes per day (only daily smokers) } \\
\hline 10 or less & $1.04(0.62-1.74)$ & $1.61(0.89-2.89)$ & $1.74(0.98-3.09)$ \\
\hline $11-15$ & $1.43(0.86-2.36)$ & $1.87(1.08-3.25)^{*}$ & $1.92(1.09-3.39)^{*}$ \\
\hline $16-20$ & $1.25(0.75-2.09)$ & $1.62(0.93-2.85)$ & $2.05(1.15-3.66)^{*}$ \\
\hline More than 20 & 1.00 & 1.00 & 1.00 \\
\hline \multicolumn{4}{|l|}{ Quit attempt made last year } \\
\hline Yes & $0.97(0.69-1.35)$ & $1.09(0.69-1.73)$ & \\
\hline No & 1.00 & 1.00 & \\
\hline \multicolumn{4}{|c|}{ Smoking cessation pharmacotherapy used last year } \\
\hline Yes & $1.08(0.67-1.72)$ & $0.87(0.47-1.61)$ & \\
\hline No & 1.00 & 1.00 & \\
\hline \multicolumn{4}{|c|}{ Avoid smoking bans } \\
\hline \multicolumn{4}{|c|}{ Having a total smoking ban at home } \\
\hline Yes & $0.46(0.31-0.68)^{* * *}$ & $0.41(0.26-0.64)^{* * * *}$ & $0.46(0.29-0.72)^{* * *}$ \\
\hline No & 1.00 & 1.00 & 1.00 \\
\hline \multicolumn{4}{|c|}{ Smoking in bar/pub last visit } \\
\hline Yes & $0.64(0.46-0.90)^{*}$ & $0.78(0.52-1.17)$ & \\
\hline No & 1.00 & 1.00 & \\
\hline Price awareness ${ }^{\mathrm{a}}$ & $1.08(0.93-1.26)$ & $1.14(0.93-1.39)$ & \\
\hline Enjoy smoking ${ }^{\mathrm{a}}$ & $1.09(0.90-1.31)$ & $1.01(0.81-1.26)$ & \\
\hline $\begin{array}{l}\text { a } \text { On a scale from } 1 \text { to } 5 . \\
{ }^{*} p<0.05 . \\
p<0.01 . \\
p<0.001 .\end{array}$ & & & \\
\hline
\end{tabular}

e-cigarettes in the Netherlands. We found a decrease in reported awareness of e-cigarettes between 2008 and 2013, likely due to the prohibition of advertising. This was also associated with a parallel decline in current use, although both trends had turned around by 2014, following the easing of restrictions in 2012 and the reappearance of advertising in 2013 which took place after the measurement in 2013. The massive increase in use between 2013 and 2014 is particularly notable. This increase in use is also in line with trends in other countries (Dockrell et al., 2013; Yong et al., 2014). With regard to the self-reported reasons for use, we found that e-cigarette users report to use them mainly to reduce their smoking or because they consider e-cigarettes as being less harmful than regular cigarettes. This is in line with previous research (Adkison, O'Connor, BansalTravers, et al., 2013; Dawkins et al., 2013; Goniewicz et al., 2013; Kralikova et al., 2013; Zhu et al., 2013). Price was also clearly important, as a majority (61\%) reported that they started to use ecigarettes because they considered them to be cheaper than regular cigarettes, and concerns about the price of cigarettes were similarly positively associated with trial. Few other studies included price as a possible motivation to use e-cigarettes, and these found mainly lower percentages (Etter \& Bullen, 2011; Zhu et al., 2013). In our study, few smokers report using e-cigarettes as an alternative to quitting, while most report using them to reduce the number of cigarettes smoked per day, which is reassuring. Smokers seem to be aware of the dangers of smoking for their health and regarded ecigarettes as an alternative or replacement to decrease these health risks, a finding also reported in other studies (Dockrell et al., 2013; Etter, 2010; Etter \& Bullen, 2011). It is notable that most are using e-cigarettes even though they do not prefer the taste of e-cigarettes.

Regarding the socio-demographic characteristics of e-cigarette users, young people and men were more likely to have ever tried e-cigarettes compared to older age groups and women. Previous studies also found that young people more often tried e-cigarettes compared to older groups (Choi \& Forster, 2013; Dockrell et al., 2013; Kralikova et al., 2013; Zhu et al., 2013). This is notable because trends in tobacco smoking show that young people smoke decreasing amounts of tobacco in the Netherlands (Bruggink, 2013). The association between ever trying e-cigarettes and gender was investigated in previous studies as well, but with mixed results (Adkison, O'Connor, Bansal-Travers, et al., 2013; Choi \& 
Forster, 2013; Kralikova et al., 2013; Regan et al., 2013; Zhu et al., 2013). In contrast to the results of trial use, current use was not higher among men, and it was lower among young smokers than older smokers. Apparently, young people and men are more likely to try e-cigarettes, but not to keep using them. This is in accordance with previous research showing that men and young people tend to experiment more with new products (CDC, 2010). With respect to education, we found that smokers with a moderate educational background were less likely to currently use e-cigarettes than highly educated smokers. Previous research regarding educational differences in current use showed no clear results (Adkison, O'Connor, Bansal-Travers, et al., 2013; Regan et al., 2013; Zhu et al., 2013). No differences in use according to income were found in the present study.

To the best of our knowledge, this study is the first which investigated the contribution of other smoking-related factors to e-cigarette use among smokers. We found that smoking many cigarettes per day, having made a quit attempt in the last year, and having used smoking cessation pharmacotherapy in the last year was associated with ever trying e-cigarettes. This is in accordance with the most often mentioned reason for using e-cigarettes found in the present study, namely to reduce smoking regular cigarettes. The finding of a strong association with previous use of smoking cessation pharmacotherapy is of particular interest. It could be that interest is concentrated among smokers who are open to using clean forms of nicotine or that e-cigarette users previously used smoking cessation medication to quit smoking but failed and tried using e-cigarettes instead. Moreover, smokers with high price awareness of regular cigarettes were more likely to try an ecigarette. This is in accordance with reporting the lower price of e-cigarettes as a reason to start using them which was found in the present study among more than half of current e-cigarette users. If it is considered desirable to encourage smokers to switch, then keeping a large price differential may be important, as few will switch or even begin dual use on the basis of the taste, and health concerns may not be enough for many.

Regarding the associations with current use, only a few variables remained significantly associated in the analyses. A positive association between current use and harm awareness for the health of other people suggests that smokers might use e-cigarettes to protect their environment from tobacco smoke exposure. Smokers who smoked many cigarettes per day were more likely to try an e-cigarette, while current use was associated with smoking relatively fewer cigarettes per day. It is possible that these smokers smoke fewer cigarettes because of the dual use with e-cigarettes, but we could not determine this with the present study. Furthermore, respondents who do not smoke at home were less likely to keep using e-cigarettes. A possible explanation is that implementing a total smoking ban at home includes e-cigarettes. Future research should take this into account and should look into reasons to keep using e-cigarettes among current users.

\section{Strengths and limitations}

An important strength of the current design was that we used a sample from the general population of smokers. Some other studies recruited users via forums or websites for e-cigarettes or via shops where users bought e-cigarettes, which could bias the results.

Several important limitations should be taken into consideration when interpreting our results. First, the analysis of use relied on cross-sectional data, making causal hypothesising impossible. Second, the sample of current e-cigarette users was relatively small, which could have resulted in limited power to identify small but potentially important associates of e-cigarette use. However, the results give an important first impression of the group of current Dutch e-cigarette users and provide a starting point for future research about factors that determine whether people keep using e-cigarettes and why. Third, the reasons to use e-cigarettes were listed; respondents had no option to fill in other reasons, so some reasons for use may be missing. Fourth, the exact timing of use of smoking cessation pharmacotherapy was not measured. Respondents were only asked whether they used medication in the last year. Future research should investigate whether smokers started using e-cigarettes before, during or after using medication to clarify their motivation for using e-cigarettes even more.

\section{Conclusion}

E-cigarettes are increasingly used by Dutch smokers. Awareness and use of e-cigarettes seemed to be capable of being influenced by mass media advertisements. The findings from the present study showed that commonly endorsed motivations for current e-cigarette use were to reduce tobacco smoking and because ecigarettes are considered less harmful than tobacco cigarettes, but it remains uncertain how many smokers are successful in reducing or quitting smoking due to e-cigarettes. Therefore, it is vitally important that long-term health and cessation effects of e-cigarettes are examined and communicated to the public.

\section{Competing interests}

None.

\section{Funding}

This study was supported by a grant from the Netherlands Organisation for Health Research and Development (ZonMw), 5051505-98-120.

\section{References}

Adkison, S. E., O'Connor, R. J., Bansal-Travers, M., Hyland, A., Borland, R., Yong, H. H. et al. (2013). Electronic nicotine delivery systems: International tobacco control four-country survey. American Journal of Preventive Medicine, 44(3), 207-215. http://dx.doi.org/10.1016/j.amepre.2012.10.018

Adkison, S. E., O'Connor, R. J., Borland, R., Yong, H. H., Cummings, K. M., Hammond, D., et al. (2013). Impact of reduced ignition propensity cigarette regulation on consumer smoking behavior and quit intentions: Evidence from 6 waves (2004-11) of the ITC Four Country Survey. Tobacco Induced Diseases, 11(1), 26. http://dx.doi.org/10.1186/1617-9625-11-26

Bodner, T.E.(2008). What improves with increased missing data imputations? Structural Equation Modeling: A Multidisciplinary Journal, 15, 651-675.

Borland, R. (2011). Electronic cigarettes as a method of tobacco control. British Medical Journal, 343, d6269. http://dx.doi.org/10.1136/bmj.d6269

Borland, R., Yong, H. H., Cummings, K. M., Hyland, A., Anderson, S., \& Fong, G. T. (2006). Determinants and consequences of smoke-free homes: Findings from the International Tobacco Control (ITC) Four Country Survey. Tobacco Control, 15(Suppl. 3), iii42-iii50. http://dx.doi.org/10.1136/tc.2005.012492

Bruggink, J.-W. (2013). Ontwikkelingen in het aandeel rokers in Nederland sinds 1989. Heerlen: Centraal Bureau voor de Statistiek.

Caponnetto, P., Campagna, D., Cibella, F., Morjaria, J. B., Caruso, M., Russo, C., et al. (2013). EffiCiency and Safety of an eLectronic cigAreTte (ECLAT) as tobacco cigarettes substitute: A prospective 12-month randomized control design study. PLOS ONE, 8(6), e66317. http://dx.doi.org/10.1371/journal.pone.0066317

CDC. (2010). Any tobacco use in 13 States - Behavioral risk factor surveillance system, 2008. MMWR Morbidity and Mortality Weekly Report, 59, 946-950.

Choi, K., \& Forster, J. (2013). Characteristics associated with awareness, perceptions, and use of electronic nicotine delivery systems among young US Midwestern adults. American Journal of Public Health, 103(3), 556-561. http://dx.doi.org/ 10.2105/ajph.2012.300947

Dawkins, L., Turner, J., Roberts, A., \& Soar, K. (2013). ‘Vaping' profiles and preferences: An online survey of electronic cigarette users. Addiction, 108(6), 1115-1125. http://dx.doi.org/10.1111/add.12150

Dockrell, M., Morison, R., Bauld, L., \& McNeill, A. (2013). E-cigarettes: Prevalence and attitudes in Great Britain. Nicotine and Tobacco Research, http://dx.doi.org/10. 1093/ntr/ntt057

Driezen, P., \& Thompson, M. E. (2011). Comparing policy measures across multiple ITC countries: Adjusting for time-in-sample. University of Waterloo.

Etter, J. F. (2010). Electronic cigarettes: A survey of users. BMC Public Health, 10, 231. http://dx.doi.org/10.1186/1471-2458-10-231 
Etter, J. F., \& Bullen, C. (2011). Electronic cigarette: Users profile, utilization, satisfaction and perceived efficacy. Addiction, 106(11), 2017-2028. http://dx.doi.org/ 10.1111/j. 1360-0443.2011.03505.x

Farsalinos, K. E., \& Stimson, G. V. (2014). Is there any legal and scientific basis for classifying electronic cigarettes as medications? International Journal of Drug Policy, 25(3), 340-345. http://dx.doi.org/10.1016/j.drugpo.2014.03.003

Fong, G. T., Cummings, K. M., Borland, R., Hastings, G., Hyland, A., Giovino, G. A., et al. (2006). The conceptual framework of the International Tobacco Control (ITC) Policy Evaluation Project. Tobacco Control, 15(Suppl. 3), iii3-iii11. http://dx.doi.org/10.1136/tc.2005.015438

Goniewicz, M. L., Lingas, E. O., \& Hajek, P. (2013). Patterns of electronic cigarette use and user beliefs about their safety and benefits: An Internet survey. Drug and Alcohol Review, 32(2), 133-140. http://dx.doi.org/10.1111/ j.1465-3362.2012.00512.x

Hajek, P., Etter, J. F., Benowitz, N., Eissenberg, T., \& McRobbie, H. (2014). Electronic cigarettes: Review of use, content, safety, effects on smokers and potential for harm and benefit. Addiction, http://dx.doi.org/10.1111/add.12659

Hitchman, S. C., Mons, U., Nagelhout, G. E., Guignard, R., McNeill, A., Willemsen, M. C., et al. (2012). Effectiveness of the European Union text-only cigarette health warnings: Findings from four countries. European Journal of Public Health, 22(5), 693-699. http://dx.doi.org/10.1093/eurpub/ckr099

Hyland, A., Borland, R., Li, Q., Yong, H. H., McNeill, A., Fong, G. T., et al. (2006) Individual-level predictors of cessation behaviours among participants in the International Tobacco Control (ITC) Four Country Survey. Tobacco Control, 15(Suppl. 3), iii83-iii94. http://dx.doi.org/10.1136/tc.2005.013516

Kasza, K. A., Hyland, A. J., Borland, R., McNeill, A. D., Bansal-Travers, M., Fix, B. V., et al. (2013). Effectiveness of stop-smoking medications: Findings from the International Tobacco Control (ITC) Four Country Survey. Addiction, 108(1), 193-202. http://dx.doi.org/10.1111/j.1360-0443.2012.04009.x

King, B. A., Alam, S., Promoff, G., Arrazola, R., \& Dube, S. R. (2013). Awareness and ever use of electronic cigarettes among U.S. adults, 2010-2011. Nicotine and Tobacco Research, http://dx.doi.org/10.1093/ntr/ntt013

Kralikova, E., Novak, J., West, O., Kmetova, A., \& Hajek, P. (2013). Do ecigarettes have the potential to compete with conventional cigarettes? A survey of conventional cigarette smokers' experiences with e-cigarettes. Chest, http://dx.doi.org/10.1378/chest.12-2842

Mons, U., Nagelhout, G. E., Allwright, S., Guignard, R., van den Putte, B., Willemsen, M. C., et al. (2013). Impact of national smoke-free legislation on home smoking bans: Findings from the International Tobacco Control Policy Evaluation Project Europe Surveys. Tobacco Control, 22(e1), e2-e9. http://dx.doi.org/10.1136/tobaccocontrol-2011-050131

Nagelhout, G. E., Mons, U., Allwright, S., Guignard, R., Beck, F., Fong, G. T., et al. (2011). Prevalence and predictors of smoking in smoke-free bars. Findings from the International Tobacco Control (ITC) Europe Surveys. Social Science and Medicine, 72(10), 1643-1651. http://dx.doi.org/10.1016/j.socscimed.2011.03.018

Nagelhout, G. E., van den Putte, B., Allwright, S., Mons, U., McNeill, A., Guignard, R. et al. (2014). Socioeconomic and country variations in cross-border cigarette purchasing as tobacco tax avoidance strategy. Findings from the ITC Europe
Surveys. Tobacco Control, 23(Suppl. 1), i30-i38. http://dx.doi.org/10.1136| tobaccocontrol-2012-050838

Nagelhout, G. E., van den Putte, B., de Vries, H., Crone, M., Fong, G. T., \& Willemsen, M. C. (2012). The influence of newspaper coverage and a media campaign on smokers' support for smoke-free bars and restaurants and on secondhand smoke harm awareness: Findings from the International Tobacco Control (ITC) Netherlands Survey. Tobacco Control, 21(1), 24-29. http://dx.doi.org/10.1136/tc.2010.040477

Nagelhout, G. E., Willemsen, M. C., Thompson, M. E., Fong, G. T., van den Putte, B., \& de Vries, H. (2010). Is web interviewing a good alternative to telephone interviewing? Findings from the International Tobacco Control (ITC) Netherlands survey. BMC Public Health, 10, 351. http://dx.doi.org/10.1186/1471-2458-10-351

Odum, L. E., O'Dell, K. A., \& Schepers, J. S. (2012). Electronic cigarettes: Do they have a role in smoking cessation? Journal of Pharmacy Practice, 25(6), 611-614. http://dx.doi.org/10.1177/0897190012451909

Pearson, J. L., Richardson, A., Niaura, R. S., Vallone, D. M., \& Abrams, D. B. (2012). eCigarette awareness, use, and harm perceptions in US adults. American Journal of Public Health, 102(9), 1758-1766. http://dx.doi.org/10.2105/ajph.2011.300526

Pepper, J. K., \& Brewer, N. T. (2013). Electronic nicotine delivery system (electronic cigarette) awareness, use, reactions and beliefs: A systematic review. Tobacco Control, http://dx.doi.org/10.1136/tobaccocontrol-2013-051122

Regan, A. K., Promoff, G., Dube, S. R., \& Arrazola, R. (2013). Electronic nicotine delivery systems: Adult use and awareness of the 'e-cigarette' in the USA. Tobacco Control, 22(1), 19-23. http://dx.doi.org/10.1136/tobaccocontrol-2011-050044

Richardson, A Pearson, J., Xiao, $\mathrm{H}$., Stalgaitis, C, \& Vallone, D. (2014). Prevalence, harm perceptions, and reasons for using noncombustible tobacco products among current and former smokers. American Journal of Public Health, 104(8), 1437-1444. http://dx.doi.org/10.2105/ajph.2013.301804

Siahpush, M., Borland, R., \& Yong, H. H. (2007). Sociodemographic and psychosocial correlates of smoking-induced deprivation and its effect on quitting: Findings from the International Tobacco Control Policy Evaluation Survey. Tobacco Control, 16(2), e2. http://dx.doi.org/10.1136/tc.2006.016279

Stimson, G. V., Thom, B., \& Costall, P. (2014). Disruptive innovations: The rise of the electronic cigarette. International Journal of Drug Policy, 25(4), 653-655. http://dx.doi.org/10.1016/j.drugpo.2014.05.003

Thompson, M. E., Fong, G. T., Hammond, D., Boudreau, C., Driezen, P., Hyland A., et al. (2006). Methods of the International Tobacco Control (ITC) Four Country Survey. Tobacco Control, 15(Suppl. 3), iii12-iii18. http://dx.doi.org $10.1136 /$ tc. 2005.013870

WHO. (2009). Study group on tobacco product regulation. Geneva: World Health Organization.

Yong, H. H., Borland, R., Balmford, J., McNeill, A., Hitchman, S., Driezen, P., et al (2014). Trends in e-cigarette awareness, trial, and use under the different regulatory environments of Australia and the UK. Nicotine and Tobacco Research http://dx.doi.org/10.1093/ntr/ntu231

Zhu, S. H., Gamst, A., Lee, M., Cummins, S., Yin, L., \& Zoref, L. (2013). The use and perception of electronic cigarettes and snus among the U.S. population. PLOS ONE, 8(10), e79332. http://dx.doi.org/10.1371/journal.pone.0079332 